\title{
"I Kept Questioning It in the First 6th Months": The Process of AAC Acceptance in Parents of Children with Complex Communication Needs
}

\author{
HyunJu Park \\ Division of Speech-Language Pathology, Gachon University, Seongnam, Korea
}

Correspondence: HyunJu Park, PhD

Division of Speech-Language Pathology, Gachon

University, 1342 Seongnam-daero, Sujeong-gu,

Seongnam 13120, Korea

Tel: + 82-31-750-8881

Fax: +82-31-750-8837

E-mail: phj8747@gachon.ac.kr

Received: January 20, 2021

Revised: February 15, 2021

Accepted: February 15, 2021

\begin{abstract}
Objectives: This study, which focused on the experiences of parents of children with complex communication needs, aimed to conduct an integrated examination of the acceptance process for augmentative and alternative communication (AAC) and the factors that affected that process. Methods: One-on-one in-depth interviews were conducted with 15 parents who had come to accept AAC through the intervention experiences of their children with developmental disabilities. The collected data was then analyzed using a methodology of qualitative research known as the grounded theory approach. Results: First, 181 concepts and 56 subcategories sorted into 18 categories were extracted through open coding. Axial coding was then applied in the construction of a paradigm model and phasic process of change. During the AAC acceptance process, parents experienced the central phenomenon of 'doubt and hesitation', and appeared to pass through stages of acknowledgment, confirmation, investigation, effort, and acceptance. Finally, selective coding was used to obtain the core category of 'genuine experiences of communication between two agents, achieved through time and patience.' Conclusion: This study confirmed that parent competency, comprising knowledge, skills, and attitudes, are crucial to the successful implementation of AAC intervention for children with complex communication needs. Practical implications for strengthening parent competencies and facilitating acceptance of AAC are discussed based on the results of the study.
\end{abstract}

Keywords: Augmentative and alternative communication, AAC, Acceptance process, Grounded theory, Parents
'Complex communication needs (CCN),' a term which has replaced the long-used 'severe communication impairments' are said to exist when the means of communication presently available to an individual cannot alone satisfy the individual's daily communication needs (Beukelman \& Mirenda, 2013; Justice \& Redle, 2013). Despite the recommendation of augmentative and alternative communication (AAC) for children with $\mathrm{CCN}$ arising from developmental disabilities, AAC is not readily accepted by significant stakeholders such as parents, speech-language pathologists, and special education teachers (Johnson, Inglebret, Jones, \& Ray, 2006; Moorcroft, Scarinci, \& Meyer, 2019a, 2019b; Park, 2020;
Park, Lee, \& Park, 2020; Shin \& Lee, 2016). As AAC provides many advantages for children with $\mathrm{CCN}$, and as the utilization of AAC in early intervention is especially important to producing a net positive effect (Beukelman \& Mirenda, 2013; Drager, Light, \& McNaughton, 2010), the problem of AAC acceptance among stakeholders is one requiring in depth examination.

The terms 'acceptance', 'rejection', and 'abandonment' have often been employed in relation to the issue of AAC acceptance. According to Johnson et al. (2006), the ways in which these terms are used within the body of AAC literature differ from their conventional usages. By their definition, 'rejection' refers to the dismissal 
of AAC options immediately upon their suggestion, and 'abandonment' to the initial acceptance of AAC systems followed by discontinuation of usage despite their necessity. 'Acceptance' signifies that the family continues to make use of AAC systems to some degree (Moorcroft et al., 2019b).

The acceptance and appropriate usage of AAC by direct stakeholders is vital to the successful implementation of AAC intervention for children with CCN. With this understanding, several efforts have been made to facilitate AAC acceptance in stakeholders and to identify the barriers obstructing the usage of AAC systems (Baxter, Enderby, Evans, \& Judge, 2012; Johnson et al., 2006; Moorcroft, Scarinci, \& Meyer, 2018). Johnson et al. (2006) examined the factors affecting the success or abandonment of AAC among speech-language pathologists (SLPs), while Baxter et al. (2012) reviewed the facilitating and obstructing factors associated with the usage of high-tech AAC devices, and Moorcroft et al. (2018) conducted a systematic review of the facilitating and obstructing factors associated with the use of low- and no-tech AAC systems.

Recently, studies have been conducted both domestically (in South Korea) and overseas in order to thoroughly examine the factors affecting the acceptance, rejection, or abandonment of AAC through the experiences of parents and SLPs (Moorcroft et al., 2019a, 2019b; Park, 2020; Park et al., 2020). On the overseas side is the work of Moorcroft and her colleagues: Moorcroft et al. (2019a) began by collecting interview data from 12 parents of children with $\mathrm{CCN}$, then analyzing the factors that influenced those parents to reject or abandon AAC. Ultimately, 4 themes were extracted: 'parents' lack of emotional readiness', 'extraneous work for parents', 'children not using AAC for the purpose of communication', and 'dissatisfaction with the AAC system itself'. A follow-up study by these researchers analyzing the experiences of 16 SLPs (Moorcroft et al., 2019b) revealed 6 themes affecting parental acceptance, rejection, or abandonment of AAC, i.e. "(a) The Way Parents View Their Child, (b) Parents' Views on AAC Intervention, (c) Support Networks Around Parents, (d) The Capacity of and Demands on Parents, (e) Services Provided by SLPs, and (f) Specific Features of AAC Systems" (p. 193). Based on the results of their study, Moorcroft and her colleagues concluded that SLPs' promotion of AAC acceptance in parents of children with CCN requires consideration not only of the child with $\mathrm{CCN}$, the parents, and the availability of the AAC system, but also of the clinical limitations of the SLPs involved.

Domestically, Park (2020) examined the AAC intervention experiences of 12 parents of children with CCN. Their results showed that factors such as 'trust in the recommender', 'financial support', and 'parent education' had a positive influence on AAC acceptance. Park et al. (2020) interviewed 6 parents who had abandoned AAC intervention for their children with CCN and analyzed the experiences and support needs that arose in the process. The results revealed that, although participating parents were all provided with tablet PCs by public assistance and possessed the positive perception that $\mathrm{AAC}$ would help the development of their children's communicative abilities, they did not know how to operate the device or the specific ways in which they could communicate with their children through the device, and so abandoned AAC without being able to properly attempt it. This study demonstrated the paramount importance of practical parental instruction in the prevention of parents' AAC abandonment.

AAC intervention supporting the communication and participation of persons with CCN proceeds as a team approach (Beukelman \& Mirenda, 2013). If the recipient of intervention in need of AAC is a child, parents play a decisive role as the most significant members of the team in accepting or rejecting AAC intervention for their child (Moorcroft et al., 2019a, 2019b; Park, 2020; Park et al., 2020). Therefore, it is crucial to heighten parents' understanding and positive perception of AAC. To this end, the positive and negative factors influencing parental AAC acceptance must be examined extensively to provide sufficient basis for the formulation of specific measures of support. Yet despite this need there is currently a lack of relevant information on the subject, which efforts must be made to correct. It would be useful to involve parents who have selected AAC as their approach to improving the communicative competencies of their children with $\mathrm{CCN}$ in research studies to examine how they came to accept AAC, and to observe how the parents' psychological, emotional, sociocultural, and economic factors functioned in the process.

In accordance with the definition established by Moorcroft et al. (2019a), this study interpreted acceptance as meaning the family utilized AAC systems to some degree. Following this criterion, 
parents who have been providing AAC intervention services to their children for at least 1 year were involved in the study (Park, 2020), and their AAC acceptance processes and intervening factors were sought out for in-depth investigation based upon vivid experiential data. As such this study adopted a qualitative rather than quantitative methodology, seeking in particular to draw its conclusions through the application of the grounded theory approach known to be well-suited to the examination of processes. To this end the researcher selected study participants by purposive sampling and conducted one-on-one interviews and sought to analyze the data thus gathered systematically in accordance with this theoretical framework. The results of this study will present not only information about the AAC acceptance process in parents of children with CCN, but also suggestions for practical intervention measures for such parents. The research problems at hand are: (a) What do parents of children with CCN experience during the AAC acceptance process? (b) How is the AAC acceptance process for parents of children with $\mathrm{CCN}$ ? and (c) What are the factors that affect the AAC acceptance process in parents of children with $\mathrm{CCN}$ ?

\section{METHODS}

\section{Participants}

The participants of this study were parents of children with CCN who had accepted AAC intervention for their children's communication impairments and continued to use it for at least 1 year. This study sought to conduct one-on-one in-depth interviews with these parents and compile data based upon their vivid lived experiences. As this study pursued the intentional collection of specific parent examples, participants were selected by purposeful sampling (Park, 2020; Park et al., 2020). Interviews with study participants were conducted to the point of theoretical saturation, following the standards of theoretical sampling (Choi, Shin, \& Song, 2016; Strauss \& Corbin, 1998).

Participant selection proceeded as follows. First, 4 intervention centers in the Seoul metropolitan area known to provide professional AAC services were recruited for the study, 2 in Seoul and 2 in the Gyeonggi province. Specifically, these were the Ewha Womans University Center for Child Development and Disability, the
Gachon University center for Integrative Development and Psychology, the Human and Communication: Center for AAC, and the EL Child Development Institute. These centers connected the researcher with parents who had implemented AAC intervention for their children for a period of 1 year or longer and were utilizing AAC to some extent within their homes. The recommended parents were then contacted by phone to gauge their interest in participation and interviews were scheduled with consenting parents. Finally, the interviews were conducted at a date, time, and place arranged according to the parents' convenience. A total of 15 parents of children with CCN were ultimately chosen as participants.

The ages of the participants were distributed as follows: 2 in their 30s, 8 in their 40s, and 5 in their 50s. The parents were relatively highly educated overall, with education levels ranging between 12 (high school graduation) and 18 years (postgraduate degrees). Their children's diagnosed disabilities included brain lesion, autism spectrum disorder (ASD), intellectual disability, hearing impairment, and language disorder; 3 of the total 15 children had multiple disabilities. The children also ranged from 7.3 (early elementary) to 16.5 (late middle school) years in age. The parents of children with CCN who participated in this study were confirmed to have communicated with their children using both aided (e.g. high-technology devices or communication boards) and unaided (e.g. gestures or sign language) methods. Finally, the parents were found to have relatively long AAC intervention experience compared to the 1 year or more intended by the study, ranging from 2.5 to 8 years in length. Their children's basic information is presented in Table 1 .

\section{Data Collection}

Materials

An interview guide was compiled for use in the interviews, consisting of open-ended questions semi-structured to prompt the sharing of a variety AAC experiences by parents of children with CCN. The interview guide was composed by first scouring precedent research for questions aligning with the purpose of this study, then collating the questions into a list and presenting them as a preliminary survey. One mother of a child with CCN due to ASD and one speech-language pathology $\mathrm{PhD}$ graduate experienced in qualitative research participated in the preliminary survey. Several 
Table 1. Participants' characteristics

\begin{tabular}{|c|c|c|c|c|c|c|}
\hline Case & Age & Education & Child's disability & Child's age & Child's sex & $\mathrm{AAC}$ use period \\
\hline$\# 1$ & 50 & Grad & $\mathrm{BL}$ & $16 ; 5$ & $\mathrm{~F}$ & 7 \\
\hline \#2 & 53 & Uni & ASD & $15 ; 10$ & M & 4 \\
\hline$\# 3$ & 56 & Uni & $\mathrm{BL}, \mathrm{ID}$ & $14 ; 8$ & $M$ & 8 \\
\hline$\# 4$ & 36 & Uni & ASD & $9 ; 6$ & M & 3 \\
\hline$\# 5$ & 45 & High & $\mathrm{BL}$ & $11 ; 3$ & $M$ & 5 \\
\hline \#6 & 36 & High & $\mathrm{HI}, \mathrm{ASD}$ & $9 ; 11$ & $\mathrm{~F}$ & 3 \\
\hline$\# 7$ & 52 & High & $\mathrm{BL}$ & $10 ; 4$ & $\mathrm{~F}$ & 4 \\
\hline$\# 8$ & 47 & Uni & $\mathrm{BL}$ & $10 ; 7$ & $\mathrm{~F}$ & 4 \\
\hline$\# 9$ & 41 & Uni & $\mathrm{BL}, \mathrm{ID}$ & $7 ; 9$ & $\mathrm{~F}$ & 2.5 \\
\hline$\# 10$ & 52 & Grad & ASD & $13 ; 6$ & $M$ & 3. 5 \\
\hline$\# 11$ & 44 & Uni & ASD & $9 ; 10$ & M & 3 \\
\hline$\# 12$ & 48 & High & ASD & $9 ; 9$ & M & 3 \\
\hline$\# 13$ & 42 & High & ID & $8 ; 7$ & $M$ & 4 \\
\hline$\# 14$ & 41 & Uni & ASD & $9 ; 11$ & $M$ & 3 \\
\hline$\# 15$ & 41 & Col & LD & $7 ; 3$ & $\mathrm{~F}$ & 3 \\
\hline
\end{tabular}

All values are in years.

Grad=graduate school; Uni= university; High=high school; Col=College; $\mathrm{BL}=$ brain lesions; $\mathrm{ASD}=$ autism spectrum disorder; ID= intellectual disability; $\mathrm{HI}=$ hearing impairment; $\mathrm{LD}=$ language disorder.

questions were deleted or added in accordance with participant responses and feedback to produce the final set of questions.

The questions included in the interview guide consisted largely of the 4 sections of 'general details', 'experiences with conventional speech therapy pre-AAC implementation', 'experiences post-AAC implementation', and 'expectations for their children and the role of parents'. Questions related to general details were used in the introductory segment of the interview in order to alleviate the participants' first-meeting unfamiliarity and tension and to progress the interview naturally (Brad, Skinner, Roberts, \& Hennon, 2006; Park, 2020), and consisted of items such as: "What are the things [child] likes/dislikes?", "What is [child]'s temperament/ personality like?", and "What makes [child] angry?". Questions related to experiences with conventional speech and language therapy pre-AAC implementation included: "When did you start speech and language therapy?", "How satisfied were you with the speech and language therapy?", and "What was the purpose of the speech and language therapy?". In relation to experiences postAAC implementation, questions were asked such as: "Which AAC system are you currently using?", "Do you have any special experiences related to AAC?", "Is there anything you more you would like from AAC?", and "What does AAC mean to you/your child?". Finally, questions related to expectations for their children and the role of parents included: "What are your future hopes or goals for [child]?" and "What do you think your role is as [child]'s parent?".

\section{Procedure}

This study was carried out with the approval of the Gachon University Institutional Review Board. Interviews were conducted for the purpose of data collection beginning in the summer of 2019 and ending in early winter 2020. The relatively long interview period is due in part to repeated delays in interview scheduling accompanying the strengthening of governmental social distancing initiatives in response to the spread of severe acute respiratory syndrome coronavirus-2 (SARS CoV2).

All interviews were conducted after obtaining the participant's consent, and each participant was interviewed in a minimum of 2 to a maximum of 5 one-on-one sessions until all questions were answered completely. For the initial interview, 13 of the 15 participants took part in face-to-face sessions; after repeated delays in scheduling accompanying the strengthening of governmental social distancing initiatives in response to the spread of SARS CoV2, the other 2 participants were ultimately given contact-free interviews via email and phone calls. In the case of face-to-face interviews, the time and place were arranged according to the partici- 
pant's convenience. Of the 13 parents who participated in face-toface interviews, 10 chose to be interviewed at a quiet café near their home. Of the remaining 3 participants, 2 used a vacant room in their child's intervention center, and the last was interviewed at their child's school. The time required per interview varied, ranging from approximately 40 minutes to 2 hours and 30 minutes depending on the participant's situation. The follow-up interviews were conducted both face-to-face and contact-free depending on the participant. As agreed upon beforehand, the contents of each interview were recorded by smartphone. Finally, in the case that additional information or confirmation was needed, insufficient information was supplemented through the exchange of emails, text messages, and KakaoTalk (an instant messaging application) messages.

\section{Transcription}

All interviews were recorded using the recording function of an LG-F700S model smartphone and then transcribed using the Microsoft Word program within 1 week of the interview's completion. While the transcription was primarily done by the researcher, 1 research assistant pursuing a master's degree in speech-language pathology transcribed part of the participants' interviews. As a holder of a master's degree in counseling, the research assistant had previous experience in writing qualitative research papers. To ensure accuracy, the researcher and research assistant also exchanged transcriptions to recheck whether the transcribed text matches the audio recordings. Transcriptions of interviews conducted over the phone were initially processed by uploading the call recordings to Daglo, an AI speech recognition dictation service, then inspected and corrected by the researcher in comparison with the audio files.

The transcriptions thus produced were emailed individually to all participants. The final transcription, completed in accordance with the participants' review and permission of use, corresponded to 581 pages of $\mathrm{A} 4$ paper.

\section{Data Analysis}

The data for this study was analyzed in keeping with the procedure presented by grounded theory of Strauss and Corbin (1998), i.e. coding the transcription in the order of open coding, axial coding, and selective coding. First, in the open coding process, concepts were identified from the raw data by a combination of searching for significant statements and continuous comparison, named, and then grouped into categories based on relevance. Concepts were named by either directly quoting participant statements or else assigning meaningful interpretive titles (Park, Kim, Bang, Oh, \& Lim, 2016). Next, category analysis and process analysis were executed through axial coding. A paradigm model of the relationships between the categories was constructed by category analysis, while process analysis sought to track the participants' process of change over time by examining the connections between the actions and interactions appearing in the paradigm model (Strauss \& Corbin, 1998). Finally, all categories were combined, and the participants' experiences summarized in order to derive by selective coding the core category representing the central theme of the study.

\section{Efforts for Reliability and Validity of Study}

This study aimed to secure the reliability and validity of its data collection and analysis. As mentioned above, the data analysis process of the grounded theory methodology undergoes the two stages of transcription and coding in order to process the contents of the interviews into an analyzable form (Park et al. 2016).

A speech-pathology master's degree student with experience in qualitative research was recruited as a research assistant during the transcription process, helping conduct peer review as well as distributing transcriptions to the participants and instructing them in member checking (Park, 2020). Member checking was implemented via email and KakaoTalk. Examples of the responses sent by study participants include: "Thank you for your hard work. I've read it all through from start to finish. Please proceed as intended." and "The COVID situation is worsening to the point that it seems a blessing we pushed ahead with our meetings early on. I felt as though I was as tongue-tied in my secondary interview as I was in my initial one, so I made some minor edits to help with comprehension. Thank you for taking the time out of your busy schedule to do this great study." Another participant sent several photos over KakaoTalk demonstrating changes in her child's abilities and problem behaviors, suggesting they might be of use to the study. These, validity-raising operations were enacted as efforts to 
satisfy the truth value required particularly by qualitative research (Guba \& Lincoln, 1981).

The researcher then discussed the coding process and analytic results with an expert qualitative researcher in possession of a speech-language pathology $\mathrm{PhD}$ and over 10 years of clinical experience. Part of the combined concepts and some names of concepts and categories were modified in this process. This reliabilityraising operation was enacted as an effort to satisfy the consistency required by qualitative research (Guba \& Lincoln, 1981).

In addition, one parent of a child with $\mathrm{CCN}$ who had not participated in the study was shown the results and asked to review them in light of their own experiences, to which the parent responded "They're similar. It's astonishing that these experiences were organized so neatly and clearly. We're really working very hard and are in serious need of expert assistance." This process of review was implemented as an effort to satisfy standards of applicability as defined by Guba and Lincoln (1981).

Finally, the researcher made a continuous effort throughout the period of research extending over a year to exclude internalized biases from the results of the study.

\section{RESULTS}

\section{Categorization of Concepts Related to the AAC Acceptance Process of Parents}

A total of 181 concepts were extracted as a result of open coding performed through data analysis; these concepts were classified into 56 subcategories, such as: 'was recommended AAC', 'skepticism during the first 6 months', 'clinging to the means of speech', 'lack of information', 'encountering real cases', 'child's favor', 'attention turning to communication', 'feeling urgency', 'using AAC', and 'enjoying communication'. These subcategories were classified into 18 categories, including 'learning about AAC', 'doubt

Table 2. Examples of categorization regarding parents' AAC acceptance experiences

\begin{tabular}{lrc}
\hline Concepts & Subcategory & Category \\
\hline Effort to communicate with child & Assigned role of & Acknowledged as \\
- Ensures child is not excluded & communicator & $\begin{array}{c}\text { agent of com- } \\
\text { munication }\end{array}$ \\
Child left to make own decisions & Agency acknowl- & \\
- Provision of options & edged & \\
Lack of agency acknowledged & Given control of & \\
- Exchange of conversational control & conversation & \\
\hline
\end{tabular}

\begin{tabular}{|l|}
\hline Intervening conditions \\
\hline - 6 Months of patience \\
- Parents' internal factors \\
- Availability of external \\
resources \\
- Child's positive feedback \\
\hline
\end{tabular}

\begin{tabular}{|c|c|c|c|}
\hline Causal conditions & Central phenomenon & Action/interaction & Consequences \\
\hline - Learning about AAC & - Doubt and hesitation & $\begin{array}{l}\text { - Confirming the } \\
\text { importance of } \\
\text { communication } \\
\text { through AAC } \\
\text { - Acknowledging } \\
\text { limitations } \\
\text { - Recognizing problems } \\
\text { in parenting attitudes } \\
\text { - Actively searching for } \\
\text { information } \\
\text { - Actively attempting } \\
\text { AAC }\end{array}$ & $\begin{array}{l}\text { - Sharing the joy of } \\
\text { communication } \\
\text { - Recognition of child } \\
\text { as an agent of } \\
\text { communication } \\
\text { - Positive perception of } \\
\text { child's potential } \\
\text { - Hope granted by AAC }\end{array}$ \\
\hline
\end{tabular}

Figure 1. Paradigm model of parents' AAC acceptance process. 
and hesitation', 'hopes and fears about speech', 'child's positive feedback', and 'acknowledged as agent of communication'. Specific examples of the process of categorization are shown in Table 2.

\section{The AAC Acceptance Process in Parents}

Axial coding recombining data in new ways by forming connections between categories was performed in order to examine in detail the AAC acceptance process in parents of children with CCN (Strauss \& Corbin, 1998). The results of the axial coding are as follows.

\section{Construction of paradigm model}

The categories derived from the results of open coding were classified as causal conditions, central phenomenon, contextual conditions, intervening conditions, action/interaction, and consequences. The extracted categories and constructed paradigm model are as shown in Figure 1.

\section{Causal conditions}

Causal conditions are events or variables that produce or influence the production of a certain phenomenon, referring to the conditions that directly cause the central phenomenon (Park et al., 2016). The causal condition of this study was 'Learning about AAC'. Research participants stated that they first encountered AAC through other mothers' accounts of their experiences or through parental education. Some also answered that they learned of $\mathrm{AAC}$ through the recommendations of acquaintances or experts.

I held out and held out until the 4th grade at 00 Elementary School and then I just couldn't. I didn't want to go to school, and neither did my child. So I just couldn't hold out any longer $\cdots$ That's how I ended up here. But when you attend a regular school, you're on your own. There was nobody to give me any parental education $\cdots$ When I came to the 00 School, they started to give me parental education. That's so exciting. That's how in the 5th grade, my child was at school during the morning anyway, so I took all the education programs held in the mornings $\cdots$ But then now one day Teacher 000 said they're doing AAC. [I thought,] "What on earth is AAC?" and so I listened to the lecture. (\#2)

\section{Central phenomenon}

Central phenomena are issues that participants experience due to the influences of causal conditions (Park \& Kim, 2005). In this study, the central phenomenon was identified as 'doubt and hesitation'. The participants reported experiencing concern and apprehension after being introduced to AAC, which led to them feeling doubt, ignoring recommendations, prematurely concluding it irrelevant to their child, or abandoning it after a brief attempt.

I only knew the basic definition after having heard people around me talk about it in 2016 or so. I didn't think it would be relevant to my child and didn't consider it seriously. It was in 2018 that I finally accepted it as necessary for my child. (\#9)

Originally the plan was to try it for a few more weeks into late July, but I cut even that short. I didn't want to do it. I thought it was a waste of time. But that wasn't right. It was a really good opportunity and the right path, but I didn't realize it back then... (\#10)

\section{Contextual conditions}

Contextual conditions refer to a set of sequential relations or situations that contribute to the central phenomenon (Strauss \& Corbin, 1998). In this study, contextual conditions identified as having affected the central phenomenon of 'doubt and hesitation' included 'anticipation and apprehension about speech', 'negative perceptions of AAC', and 'lack of accessibility of AAC'.

Regarding 'anticipation and apprehension about speech', participants reported a previous fixation on the idea of speech production, feeling that speech was most important and must be made to happen by any means necessary. Many also worried about delayed speech and experienced apprehension about the possibility of their child giving up on speech production entirely.

[I was worried that] speech production wouldn't happen, that [my child] would give up on speech production entirely. Especially since [child's name] has a problem on 
one side of [their] vocal cords, I thought we should put as much effort into helping [them] produce speech while [they're] still young as we put into AAC. That's why I looked into forced speech as well. (\#8)

With regard to 'negative perceptions of AAC', participants revealed that they had been influenced by prejudices about AAC such as "mistrust of using a machine [for communication]" (\#14). Participants also encountered negative feedback about AAC from experts in the field: one reported that "there are a lot of misunderstandings about AAC, like how people around me thought that AAC is only for kids who are unable to speak" (\#6), and another that "I asked another speech-language pathologist, who voiced doubts about its effectiveness". (\#5)

I was relatively determined [to seek AAC] and was able to find an experienced professional who helped us get this far before that determination was shaken, but for others, even if they opened their minds and went to the nearest expert after learning or hearing about AAC somewhere, if the expert can't show them the bigger picture they'll just give up. They might be "wowed" for a moment, but that would be the end of it. (\#1)

In relation to the 'lack of accessibility of AAC', participants responded that their decisions were influenced by the availability of information, centers specializing in AAC, AAC experts, and financial and institutional support. Participants responded that "there was not a lot of available information" (\#11), that "there were no centers nearby that offered AAC" (\#13), "there were no experts who could provide AAC" (\#3), "I wished it were cheaper, since we weren't just doing AAC alone" (\#12), "voucher provision services were limited" (\#5), and that "appropriate tools were hard to find or purchase". (\#1)

\section{Intervening conditions}

Intervening conditions are ones that alleviate or change the intensity of the central phenomenon by facilitating or obstructing actions/interactions within the context (Strauss \& Corbin, 1998). In this study, intervening conditions such as the 6 months of pa- tience', 'parents' internal factors', 'availability of external resources', and 'child's positive feedback' were found to strengthen or weaken the intensity of the central phenomenon of 'doubt and hesitation'.

The participants mentioned that their confidence wavered during the first 6 months after being introduced to AAC, emphasizing that roughly 6 months of time and patience was necessary for eventual success.

It wasn't easy for me to accept it, either $\cdots$ So I kept questioning it in the first 6 months. I didn't feel like we were getting clear results. But as we passed through those 6 to 8 months and met you, everything synergized. (\#15)

During the first six months I kept thinking, "why do I have to go here?" I kept wondering if [my child] would really be able to use this. I used to wonder if [my child] could hear, if maybe the problem was that [they] couldn't hear... but [things changed] after we'd used it for 6 months to a year. For the first few months up to the 6-month mark we barely used it at all. My child couldn't do it. Then between the 6-month and 12-month mark is when we saw drastic change. (\#11)

The process really is not easy. But once you practice enough and taste the triumph of communication, neither parent nor child will be able to tear themselves away from that sweet success. I think it probably takes about 6 months to smooth out the selection process $\cdots$ but I heard another mom say that they wished someone could just set up the AAC and let the kid just magically be able to use it right away. We told her it takes about 6 months, but she wishes she could make it happen at superspeed. She said she wished someone could do that initial process for them, that she didn't have this kind of energy. (\#6)

On the matter of 'parents' internal factors', some participants reported experiencing the hardship of becoming entrapped in their personal problems, including lacking energy, feeling depressed and unmotivated, the additional strain of raising multiple children, and low self-esteem as the parent of a disabled child. Personal values and opinions were also shown to be important factors, 
with participants citing AAC "a good fit with my parental values" (\#11), or feeling that AAC was "my choice and decision". (\#14)

I did my best trying everything when [my child] was younger $\cdots$ but my life is hard enough as is. Everything else is difficult enough that I can't work up the motivation to try something like AAC I've never even heard of before, I can't spare the time, not to mention the financial aspect $\cdots$ I don't want to have to try to squeeze another thing in my life, I have no motivation to do it, and I'd need the energy and stamina $\cdots(\# 1)$

Related to the 'availability of external resources', participants responded that factors that influenced them to reconsider their decisions included support from family members, support from experts, introduction to real precedent cases, and parent education. For instance, in cases that mentioned family support, emotional support and advice from the child's father made up the largest proportion of responses. Others also reported factors including "seeing the dedication of the SLP" (\#4), "being told about there was an AAC voucher" (\#7), and "being convinced by the experiences of an acquaintance met through Facebook". (\#11)

The SLP explained it to me really well. She told me, "there's something that does this and that, and I think it will help [child's name] in this and that way." ... I also attended a parent education session on AAC here at the center. I participated and made the communication board and everything. They showed us a video of a child making a sandwich. After seeing it I started thinking "wow, this really does help a lot." (\#13)

We made an app on the smartphone to fit [my child]. I think it would be hard without that kind of support. My kid doesn't know what "chocolate milk" is, because [they] learned it as "Nesquik". The SLP made a whole new icon for "Nesquik", instead of "chocolate milk". If you press the icon on the app it'll say, "Nesquik, please." It has a picture of Nesquik, too. The SLP took a completely personalized approach for us. It's so important to have the right SLP. (\#11)
Regarding the 'child's positive feedback', factors such as witnessing their child's successful experience of communication, the child's enjoyment, positive behavioral changes, improvements in social skills, and developments in language abilities were also found to have had an impact on parents. Related responses included "watching my child communicating with the SLP" (\#6), "seeing how happy my child was about going to AAC therapy" (\#5), "drastic decrease in problem behaviors within a month of starting AAC" (\#2), "my child now better understands social cues" (\#7), and "my child's listening skills have improved”. (\#10)

\section{Action/interaction}

Action/interaction refers to the ways in which people react to situations, problems, or issues they come across (Park et al., 2016). Some strategies employed by the participants identified in this study included personal aspects such as 'confirming the importance of communication through AAC', 'acknowledging limitations', and 'recognizing problems in parenting attitudes', and behavioral aspects such as 'actively searching for information' and 'actively attempting AAC.'

In relation to 'confirming the importance of communication through AAC', participants' responses that they "realized how many opportunities children are deprived of when they cannot communicate" (\#6), or "recognized the lack of communication with my child, and that he was constantly asking to communicate but I couldn't understand” (\#2) made it clear that they were able to identify their children's problems with communication and began to expend more attention communicating with their children. They were also able to understand that communication can happen through a variety of methods, as visible in the responses of a participant who "...realized that communication doesn't just consist of speech, and that my child was able to communicate in her own language" (\#1), and a participant whose "....whole family accepted that there can be different methods of communicating". (\#9)

In relation to 'acknowledging limitations', participants reported that they came to acknowledge their children's limitations as they grew older, changed in personality, or saw the worsening of problem behaviors. Factors such as a lack of progress in ongoing speech 
therapy or a widening gap between receptive and expressive language also led them to accept the limitations of existing methods of treatment.

Regarding the 'recognizing problems in parenting attitudes', many participants responded that they realized during the process of AAC that they had not sufficiently considered how their children felt, as with participants who mentioned that they had "denied my child's identity" (\#6) or "hadn't been seeing things from my child's perspective, focusing more on my expectations and inner hurts". (\#9) Some participants also came to reflect on their past parenting attitudes and accept their children's situations.

I think mothers tend to want something the child can learn through repetition. And they want their children to become similar to kids without disabilities. But if you can shift your goal to just communicating with your child, they don't have to feel pressured $\cdots$ I think it helps both of us grow without stress. (\#4)

Regarding the 'actively searching for information', participants responded that they thought they couldn't afford to wait any longer and felt a sense of urgency, to which they reacted by seeking information in ways such as searching the internet, reading academic articles, listening to lectures; some also sought out experts, for example asking a special education teacher or asking an SLP.

Participants also mentioned that they began 'actively attempting AAC' through actions such as "purchasing AAC materials to try out at home" (\#13), "bringing into the house 2 laminators for creating graphic symbols, one for child and one for me use” (\#2), "sending AAC tools to my child's school" (\#11), or "asking my child's SLP to try AAC”. (\#1)

I photocopied and laminated a keyboard and pasted it to my kid's desk at school. Because [my child] knows how to use a keyboard. Speaking through this keyboard doesn' t make a big racket. I told [my child] to type this or that when friends come over to talk. It does frustrate [my child] that typos are so common when he use it, but even a rough effort will be seen by the other kids in the class. Now [my child] has begun to communicate with his classmates. The educational assistant in his class really likes it, too. (\#3)

\section{Consequences}

Consequences are the set of outcomes that occur as a result of action/interaction strategies, unrelated to the original intentions of the actor (Park et al., 2016). The four categories of consequence identified by this study were 'sharing the joy of communication', 'recognition of child as an agent of communication', 'positive perception of child's potential', and 'hope granted by AAC'.

In the category of 'sharing the joy of communication', participants affirmed that, as they came to be able to communicate with their children, they experienced the joy of communication, found friends I could open up to, formed family support groups, and participated in parent activities by taking leadership in parent groups. They also reported introducing AAC to the people around them, saying "as my child's situation improved, I went to friends or other mothers to tell them to try it" (\#15), and recommending early AAC intervention, as "the earlier they start, the wider a world the child will see". (\#3)

In relation to 'recognition of child as an agent of communications', as they worked towards communicating with their children, participants also noticed that they were "recognizing their children as agents of communication", as well as starting to provide more opportunities for their children to make their own decisions and lead conversations.

Our support group has seven families in it. The seven of us went on a trip together back when COVID-19 restrictions were lightened for a while. We got assistance from the local office to go away for two nights and three days, and I got the idea to make an AAC survey to let the kids make some of the choices. So I made one the moms could open up on their cellphones at home to let the kids choose, you can do it on Google Forms (showed interviewer the contents of the survey on her smartphone), we used that and decided on what we were going to eat and what activities to do based on the responses we gathered $\cdots$ we sent it to some other family groups as well. The kids ate jjajangmyeon and tangsuyuk, we really did everything the kids chose, based on what got the most votes. I wanted to show 
everyone how AAC makes choice possible. (\#4)

In relation to 'positive perceptions of child's potential', participants who observed that their children knew more than they had thought. And they also came to identify their children's hidden abilities and subsequently experienced a huge shift in their recognition of their children's potential.

Another thing I felt while seeing the switch to online classes (due to SARS CoV2) is that maybe our kids have more potential and capabilities than we thought. When they began online classes I'd never taught [my child] to type in Microsoft Word or anything, and they'd just started with using the tablet PC. At the beginning they weren't able to type well, and classes only happened once or twice a week so there wasn't much improvement at first, but I've seen a lot of that in the last few months. Through my own kid. (\#10)

Regarding the 'hope granted by AAC', participants experienced a departure of their initial concerns and doubts about AAC once they began use. Many began to feel hope that their children would be able to become independent communicators and began to anticipate even further possibilities for improvement. As they became able to understand their children's wants and needs, they were able to increase their emotional communication with their children. And participants felt that they broke away from a limited life and experienced an overall increase in the quality of their family life since they developed various ways to figure out what their children wanted and started to share ordinary conversations with their children.

\section{Results of process analysis}

Process analysis seeks to perform a more in-depth analysis of the continual connections between the categories that have been identified as action/interactions and the subcategories within the paradigm model, and to track the changes taking place over time (Strauss \& Corbin, 1998).

The current study followed a category analysis with a process analysis to investigate how the actions/interactions that arose as reactions and strategies to intervening conditions related to each other over time.

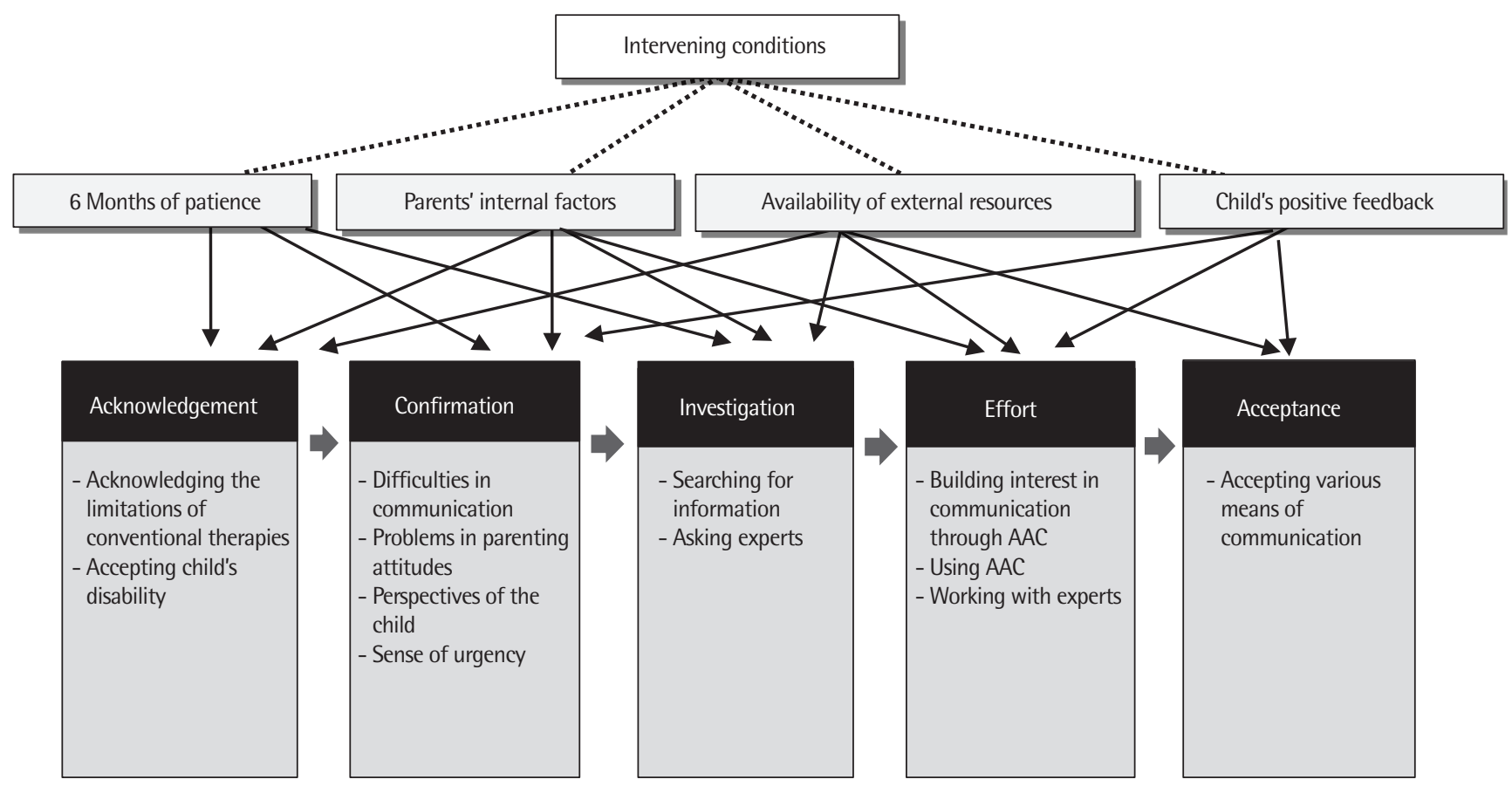

Figure 2. Analysis of the AAC acceptance process of parents. 
According to the study, participants experienced the central phenomenon 'doubt and hesitation', influenced by the causal condition 'learning about AAC' and contextual conditions 'anticipation and apprehension about speech', 'negative perceptions of AAC', and 'lack of accessibility of AAC'. The participants used several action/interaction strategies including personal strategies such as 'confirming the importance of communication through AAC', 'acknowledging limitations', and 'recognizing problems in parenting attitudes', in addition to behavioral strategies such as 'actively searching for information' and 'actively attempting AAC'. The analysis showed that the acceptance process experienced by parents of children with CCN changed as they followed five stages: acknowledgement, confirmation, investigation, effort, and acceptance. In other words, as parents came to acknowledge their children's limitations and confirm the importance of communication through AAC, they tended to grow impatient, becoming more active in searching for information about AAC and making more active efforts to attempt communication using AAC; finally, they reach the stage of complete acceptance of AAC. The parents' progression through the five stages tended to advance or stagnate according to the presence of intervening conditions such as '6 months of patience', 'parents' internal factors', 'availability of external resources', and 'child's positive feedback' (Figure 2).

\section{Identifying the Core Category in the AAC Acceptance Process of Parents}

The core category arises as the result of selective coding, the process by which categories are combined and refined. They represent the theme of the study and condenses the study into a keyword that comprehensively illustrates what the study is about (Park et al., 2016). The core category must be able to integrate other categories that have been identified (Strauss \& Corbin, 1998).

The criterion for selecting a core category include the centrality of the category, the frequency of its appearance in the data, the logic and consistency of its explanation, its potential for abstract and comprehensive theorization, and its strength of explanation (Strauss, 1987). Following these criteria, the current study identified the core category as 'genuine experiences of communication between two agents, achieved through time and patience'. The properties of the core category were identified as 'degree' and 'continuity'. The dimensions of 'degree' ranged from 'abundant' to 'scarce', while the dimensions of 'continuity' ranged from 'temporary' to 'continuous'.

\section{DISCUSSION \& CONCLUSION}

This study sought to use experiential data to comprehensively examine the AAC acceptance process in parents of children with $\mathrm{CCN}$, as well as the different factors that influenced that process. The implications for practice identified by the results are as follows.

First, many parents of children with CCN experienced the central phenomenon of 'doubt and hesitation' when they first encountered AAC. Their 'doubt and hesitation' was affected by issues of 'anticipation and apprehension about speech', 'negative perceptions of AAC', and 'lack of accessibility of AAC'. Participants reported difficulty in giving up on the idea of their children speaking, and worried that AAC would further impede their children's speech development. Parental concern of AAC impeding speech development has been widely reported in previous literature (Beukelman \& Mirenda, 2013; Cho \& Kang, 2003; Cress \& Marvin, 2003; Shin \& Lee, 2016; Park, 2020) and is a barrier frequently discussed by researchers. However, as studies have proven these fears unfounded with objective evidence (Beukelman \& Mirenda, 2013; Cress \& Marvin, 2003; Park, 2020), researchers and practitioners must make a concentrated effort to address parental concerns of impediments to speech development early on.

Negative preconceptions and misunderstandings were also found to cause doubts in the parents' acceptance processes. Some participants reported previous beliefs that AAC was something only used by children unable to speak, or that AAC could cause addiction to technology, another representative factor that has posed an obstacle to early AAC intervention for some time (Cress \& Marvin, 2003; Park, 2020; Park et al., 2020). Parent education and awareness campaigns may help alleviate myths and biases associated with AAC. In a study of adults actively participating in society through AAC systems, Im and Park (2018) recommended several specific solutions to address public misinformation on $\mathrm{AAC}$, including guest lectures in public institutions such as 
schools, mobile apps, television ads, exposure of scenes of AAC usage in dramas or films, and early exposure through the creation of AAC toys.

Difficulty of access was also a factor in parents' hesitation to accept AAC for their children. Parents particularly emphasized the difficulty of finding AAC centers or experts near their homes. One participating parent had even moved from Gyeongsang Province to Seoul to get treatment for her child, being forced to lived separately from the rest of her family. Most of the parents who participated in this study were revealed to have received negative feedback regarding AAC from speech-language pathologists (SLPs) and special education teachers. Negative feedback from experts is an issue that has been continually highlighted in the literature, demonstrating the importance of increasing experts' knowledge and skill (Goldbart \& Marshall, 2004; Lim, Park, \& Ku, 2013; Moorcroft et al., 2019a; Park, 2020; Park et al., 2020; Soto, Muller, Hunt, \& Goetz, 2001). However, the reason parents who participated in this study received much negative feedback from experts may be that they started AAC intervention before it was more conventionally used. Over the past few years, the Korean Society for Augmentative and Alternative Communication (KSAAC) and the Korean Association of Speech-Language Pathologists (KSLP) have collaborated on the production of educational programs and have assisted SLPs and special education teachers nationwide to become certified as AAC intervention experts, and universities have individually begun implementing curricula that include AAC courses. We predict that these efforts will enhance the knowledge and skill of AAC experts and improve public awareness, contributing to a great reduction in the probability that parents will receive negative feedback from experts. The problems of accessibility inflate the costs of searching for service providers or experts and of transportation, adding to parents' financial burden. Consequentially, these complications can lead parents to simply give up on AAC intervention for their children. As such, ways must be found for children with CCN to be able to easily access AAC intervention services close to home. Considering that these children are generally of school age, integrating AAC into school settings could be a good alternative (Clarke, McConachie, Price, \& Wood, 2001; Lim et al., 2013). This also aligns with the wishes of parents who participated in this study.
Secondly, the study showed that there were some factors that allowed the parents to overcome their doubts and hesitations about AAC. These factors included ' 6 months of patience', 'parents' internal factors', 'availability of external resources', and 'child's positive feedback'. Many parents found it extremely difficult to adapt to using AAC, and 6 months seemed to be a milestone at which many parents started to feel they were beginning to effectively communicate with their children. Over half of the parents reported experiencing positive changes and results between 6 months and 1 year of using AAC. A qualitative study by Piggot, Paterson and Hocking (2002) found a similar trend in their analysis of parents of children with cerebral palsy who used a home therapy program. The researchers found that it took 4 out of the 7 parents between 6 to 12 months to come to grips with using the program and become more active participants. These results suggest that supporting parents and facilitating parent motivation through positive experiences during the initial 6 months is crucial for acceptance and continued use of AAC.

Parents' internal factors were also found to influence the doubts and hesitation they experienced. Participants in this study reported that their parenting attitudes and personal values helped them overcome problems that arose. On the other hand, more than half of the parents reported that they had seen other parents with distinct parenting attitudes and values turn down recommendations for AAC or give up. The participants mentioned that parents experience numerous difficulties while raising children with $\mathrm{CCN}$, including being affected by public prejudice, depression, lack of energy, and low self-esteem. Moorcroft et al. (2019a) termed the strength to overcome and manage such difficulties "emotional resilience". Emotional resilience refers to the ability to react positively to "reverse situations" (Simon, Murphy, \& Smith, 2005). Efforts are needed to strengthen emotional resilience of parents by increasing the availability of social, financial, and educational aid. More specifically, providing counseling to the parents may help. As the difficulties of parents present latent barriers to the implementation of AAC (Baxter et al., 2012), ample time, knowledge, and resources must be invested to eliminate these barriers.

Availability of external resources was another factor that affected parents. This study showed that resources such as support from family and experts, financial aid, hearing about actual cases, and 
parent education helped alleviate parents' doubts and hesitation. These results confirm the findings of Park (2020), which showed that trust in the recommender, financial support, parent education, and objective evidence had a positive effect on parents' acceptance of AAC. However, the participants also emphasized that external resources were hard-earned through effort or luck, and that their availability is scarce. Many reported having often seen cases where other parents did not succeed in long-term AAC use because such resources were not available to them. Such reports are in line with evidence that lack of practical support and difficulty of information acquisition, among other problems, often cause parents to give up on AAC use even after having set up AAC systems (Park et al., 2020). The participants of the current study also mentioned that although AAC vouchers helped with the financial burden, there were limited agencies that provided them, and many vouchers were restricted to certain age groups. In addition, parents stated that there was still not enough objective, scientific information that parents could readily access, and stressed the need for parent education sessions centered around actual case studies and practical skills training.

'Child's positive feedback' was found to be a particularly effective factor in overcoming parents' doubts and hesitations regarding AAC. Participants had observed that their children enjoyed using AAC, showed significant reductions in problem behavior, were able to better understand social cues, and improved in their attention spans. Such results are consistent with Park (2020), in which AAC was found to greatly increase intervention satisfaction, and result in a decrease of children's problem behaviors accompanied by improvement of their language and social skills. These findings suggest that an active effort to gather and publish stories of successful cases is also crucial for improving perceptions of AAC.

Third, the participants were found to engage in several strategies in the process of accepting AAC, including 'acknowledging limitations', 'recognizing problems in parenting attitudes', 'actively searching for information', and 'actively attempting AAC'. Parents reported that prior to beginning AAC interventions, they had come to acknowledge the limitations of the interventions their children were receiving at the time and recognized the reality of their children's disability. Some participants also realized prob- lems with their current communication, problems with their parenting attitudes, or previously unnoticed wishes of their children, leading to a heightened sense of urgency. This resulted in their making a more active effort to search for information and seek help from experts. In addition, participants became more interested in communication through AAC, began to work towards using AAC, and found ways to work together with experts. Ultimately, parents were able to understand that speech was only a part of communication, and that there are many different methods that can be used to communicate with their children. Unfortunately, the study also found that in many cases, the burden of effort required throughout the acceptance process was placed solely on parents, and many parents reported that they had the most difficulty when they began to actively attempt using AAC. Parents were especially disappointed with the available tools and graphic symbols. Some of their wishes were ones also identified in Park (2020), such as the need for a wider variety of symbols that represent emotions, and better sound quality and portability of the AAC tools. Many of the participant were able to facilitate positive results despite lacking infrastructures to support their endeavors. The parents' remarkable accomplishments highlight the importance of Epley, Summers, and Turnbull (2010)'s recommendation for practitioners to acknowledge parents as collaborators with their distinct strengths, abilities and resources.

Finally, the participants were found to have experienced several positive changes from fully accepting AAC into their lives. Their experiences could be placed into categories such as 'sharing the joy of communication', 'recognition of child as an agent of communication', 'positive perception of child's potential', and 'hope granted by AAC'. For one, the parents were able to experience the joy of being able to communicate with their children, which echoes the findings of Im and Park (2018)'s study of adult users of AAC, and Park (2020)'s study of the intervention experiences of parents of children with CCN. Such experiences led participants to introduce AAC to other families in order to share the joy they felt and to create family groups to exchange AAC related information. This is a particularly encouraging trend when considering previous literature that shows that parents are strongly influenced by other parents (Donato, Shane, \& Hemsley, 2014; Park, 2020). Participants also emphasized that AAC helped them acknowledge the 
children as agents of their own lives and as people playing the role of a communicator, therefore encouraging them to provide their children with more opportunities to make their own decisions and become active agents of communication. Similarly, Park (2020) found that AAC allowed parents to fully gauge their children's potential and gave them hope that their children could one day become independent members of society. The current study also showed that parents found different types of renewed hope from AAC. They reported having more emotional connections with their children, being able to have a realistic expectation of speech production, and the quality of their family lives having improved in general. Zhan (1992) defines quality of life as the degree to which a person is satisfied with their life experiences. Participants responded that $\mathrm{AAC}$ has improved their quality of life significantly, which has also been reported in previous studies (Im \& Park, 2018; Park, 2020). Active efforts to inform AAC candidates and their primary communication partners of such positive outcomes of AAC are necessary because they can foster positive public awareness and alleviate the doubts of the families who may benefit from AAC interventions.

This study sought to collect and analyze the experiences of parents who had come to accept AAC in the course of implementing AAC intervention for their children with $\mathrm{CCN}$, in order both to gain a comprehensive understanding of the acceptance process and the factors that influenced it and to make practical recommendations based on this knowledge. The study illustrated how parents advance through the changes that accompany the different stages in the acceptance process, how they overcome barriers using internal and external resources, and ultimately experience significant results. The core category to summarize the journey made by these parents was identified as 'genuine experiences of communication between two agents, achieved through time and patience'. The results of the study particularly emphasize the need for practitioners to acknowledge the existence of a timeframe during which parents must remain patient and endure temporary frustrations, and the need to support families through this period. Another implication of the study is that the burden of care for a child with CCN should not fall solely upon individual parents or families. Efforts must be made to build systematic infrastructure, increase public awareness, and demand aid on a national level.
A limitation of the study is that the participants were all relatively highly educated, had children who were receiving interventions at a specialized AAC center from an experienced practitioner, were knowledgeable about AAC intervention, and were satisfied with their experiences. These characteristics must be considered when interpreting the results of the study. In addition, the parent interviews in this study were collected retrospectively. Future research may utilize a long-term longitudinal design to investigate the process by which parents accept or give up on AAC use and compare the results to those of the current study. A similar study investigating the lived experiences of AAC experts may also provide valuable insight and knowledge that can be used to train future AAC interventionists. The significance of this study lies in involving as its participants parents - the most important decision-makers and partners in cooperation when it comes to the implementation of AAC intervention for children with $\mathrm{CCN}$ - and in examining the AAC acceptance process through their practical experiences, identifying the positive and negative factors influencing the process, and seeking to present their specific academic and practical implications.

\section{REFERENCES}

Baxter, S., Enderby, P., Evans, P., \& Judge, S. (2012). Barriers and facilitators to the use of high-technology augmentative and alternative communication devices: a systematic review and qualitative synthesis. International Journal of Language and Communication Disorders, 47(2), 115-129.

Beukelman, D. R., \& Mirenda, P. (2013). Augmentative and alternative communication: supporting children and adults with complex communication needs (4th ed.). Baltimore: Paul H. Brookes.

Brad, N., Skinner, D., Roberts, \& Hennon, E. (2006). Communication in young children with fragile $\mathrm{x}$ syndrome: a qualitative study of mother's perspectives. American Journal of Speech-Language Pathology, 15(4), 353364.

Cho, H. J., \& Kang, S. K. (2003). A study on the application of augmentative and alternative communication for children with autism. The Korean Journal of East West Mind Science, 6(1), 1-13.

Choi, S., Shin, M., \& Song, M. (2016). A grounded theory analysis on the parenting experience of mothers of children who stutter. Communication Sciences \& Disorder, 21(4), 719-734. 
Clarke, M., McConachie, H., Price, K., \& Wood, P. (2001). Speech and language therapy provision for children using augmentative and alternative communication systems. European Journal of Special Needs Education, 16(1), 47-54.

Cress, C. J., \& Marvin, C. A. (2003). Common questions about AAC services in early intervention. Augmentative and Alternative Communication,19(4), 254-272.

Donato, C., Shane, H. C., \& Hemsley, B. (2014). Exploring the feasibility of the visual language in autism program for children in an early intervention group setting: views of parents, educators, and health professionals. Developmental Neurorehabilitation, 17(2), 115-124.

Drager, K., Light, J., \& McNaughton, D. (2010). Effects of AAC interventions on communication and language for young children with complex communication needs. Journal of Pediatric Rehabilitation Medicine, 3(4), 303310.

Epley, P., Summers, J. A., \& Turnbull, A. (2010). Characteristics and trends in family-centered conceptualizations. Journal of Family Social Work, 13(3), 269-285.

Goldbart, J., \& Marshall, J. (2004). "Pushes and pulls" on the parents of children who use AAC. Augmentative and Alternative Communication, 20(4), 194-208.

Guba, E. G., \& Lincoln, Y. S. (1981). Effective evaluation. San Francisco: Jossey-Bass Publishers.

Im, M. S., \& Park, H. (2018). "Just a minute, please": the experiences of adults using AAC. AAC Research \& Practice, 6(2), 21-44.

Johnson, J. M., Inglebret, E., Jones, C., \& Ray, J. (2006). Perspectives of speech language pathologists regarding success versus abandonment of AAC. Augmentative and Alternative Communication, 22(2), 85-99.

Justice, L. M., \& Redlle, E. (2013). Communication sciences and disorders: a clinical evidence-based approach (3rd ed.). Boston: Pearson Education Inc.

Lim, J., Park, E., \& Ku, J. (2013). A study on experiences and needs of potential AAC users' parents regarding AAC intervention services. Special Education Research, 12(3), 309-332.

Moorcroft, A., Scarinci, N., \& Meyer, C. (2018). A systematic review of the barriers and facilitators to the provision and use of low-tech and unaided AAC systems for people with complex communication needs and their families. Disability and Rehabilitation: Assistive Technology, 14(7), 710-731.

Moorcroft, A., Scarinci, N., \& Meyer, C. (2019a). “I've had a love-hate, I mean mostly hate relationship with these PODD books": parent perceptions of how they and their child contributed to AAC rejection and abandonment. Disability and Rehabilitation: Assistive Technology, 16(1), 72-82.

Moorcroft, A., Scarinci, N., \& Meyer, C. (2019b). Speech pathologist perspectives on the acceptance versus rejection or abandonment of AAC systems for children with complex communication needs. Augmentative and Alternative Communication, 35(3), 193-204.

Park, H. (2020). Parents' experiences and acceptance factors of AAC intervention for children with complex communication needs. Communication Sciences \& Disorders, 25(2), 318-333.

Park, H. B., Lee, J. Y., \& Park, H. (2020). Experiences and demands in parents of children with complex communication needs on AAC abandonment. AAC Research \& Practice, 8(2), 51-75.

Park, S. M., \& Kim, C. D. (2005). The regulation process of adolescent online game over user's behavior and intervening factors. The Korea Journal of Counseling, 6(4), 1281-1305.

Park, S. M., Kim, K. S., Bang, K. Y., Oh, Y. H., \& Lim, E. M. (2016). Counseling research course using ground theory approach. Seoul: Hakjisa.

Piggot, J., Paterson, J., \& Hocking, C. (2002). Participation in home therapy programs for children with cerebral palsy: a compelling challenge. Qualitative Health Research, 12(8), 1112-1129.

Shin, J., \& Lee, S. (2016). Parents perception on augmentative and alternative communication for students with severe disability. AAC Research \& Practice, 4(2), 1-18.

Simon, J. B., Murphy, J. J., \& Smith, S. M. (2005). Understanding and fostering family resilience. The Family Journal: Counseling and Therapy for Couples and Families, 13(4), 427-436.

Soto, G., Muller, E., Hunt, P., \& Goetz, L. (2001). Critical issues in the inclusion of students who use augmentative and alternative communication: an educational team perspective. Augmentative and Alternative Communication, $17(3), 62-72$.

Strauss, A. (1987). Qualitative analysis for social scientists. New York: Cambridge University Press.

Strauss, A., \& Corbin, J. (1998). Basics of qualitative research: grounded theory procedures and techniques (2nd ed.). Newbury Park: Sage.

Zhan, L. (1992). Quality of life: conceptual and measurement issues. Journal of Advanced Nursing, 17(7), 795-800. 


\section{국문초록}

\section{“6개월까지는 계속 물음표였어요.": 복합적인 의사소통 요구를 지닌 아동 부모의 AAC 수용 과정} 박현주

가천대학교 특수치료학과

배경 및 목적: 본 연구에서는 복합적인 의사소통 요구를 지닌 아동 부모의 경험을 중심으로 보완대체의사소통(AAC)에 대한 수용 과 정과 그 과정에 영향을 미치는 요인들을 통합적으로 살펴보고자 하였다. 방법: 자녀의 AAC 중재를 통해 이를 수용하게 된 발달장애 아 동의 부모 15 명을 대상으로 일대일 심층면담을 실시하고 자료를 수집한 후 질적 연구의 한 방법인 근거이론을 적용해 분석하였다. 결 과: 첫째, 개방코딩을 통해 181 개의 개념과 56 개의 하위 범주 및 18 개의 범주가 도출되었다. 둘째, 축코딩을 통해 부모의 AAC 수용 과정 에 대한 패러다임 모형과 단계적 변화 과정이 구축되었다. 부모들은 AAC 수용 과정에서 ‘의구심과 머뭇거림'이라는 중심현상을 경험하 였으며, 인정 단계, 확인 단계, 탐색 단계, 노력 단계, 수용 단계를 거치는 것으로 나타났다. 셋째, 선택코딩을 통해 ‘인내의 시간을 거쳐 성 취되는 두 의사소통자의 진정한 소통 경험'이라는 핵심범주가 도출되었다. 결과: 아동 대상의 AAC 중재를 성공적으로 이행하기 위해 서는 부모의 역량, 즉 지식, 기술 및 태도가 중요함을 다시 한번 확인하였다. 연구 결과에 기반하여 복합적인 의사소통 요구를 지닌 아동 부모의 $\mathrm{AAC}$ 에 대한 역량 강화와 $\mathrm{AAC}$ 수용을 촉진할 수 있는 실천적 방안들을 논의하였다.

핵심어: 보완대체의사소통, $\mathrm{AAC}$, 수용 과정, 근거이론, 부모

\section{참고문헌}

박승민, 김광수, 방기연, 오영희, 임은미 (2016). 근거이론 접근을 활용한 상담연구과정. 서울: 학지사. 박승민, 김창대 (2005). 온라인게임 과다사용 청소년의 게임행동 조절과정과 개입요인. 상담학연구, 6(4), 1281-1305. 박한빛, 이주연, 박현주 (2020). 복합적인 의사소통 요구를 지닌 아동 부모의 AAC 포기 경험과 지원 요구. 보완대체의사소통연구, 8(2), 51-75. 박현주 (2020). 복합적인 의사소통 요구를 지닌 아동의 AAC 중재에 대한 부모의 경험 및 수용 요인 탐색. Communication Sciences \& Disorders, 25(2), 318-333.

신정미, 이수향 (2016). 보완대체의사소통(AAC)에 대한 중도장애 학생 부모의 인식 조사. 보완대체의사소통연구, 4(2), 1-18.

임명순, 박현주 (2018). “조금만 기다려주세요”: 성인 보완대체의사소통(AAC) 사용자의 경험. 보완대체의사소통연구, 6(2), 21-44. 임장현, 박은혜, 구정아 (2013). 보완대체의사소통(AAC) 중재 서비스에 대한 발달장애인 부모의 요구분석. 특수교육, 12(3), 309-332. 조홍중, 강수균 (2003). 자폐아동을 위한 보완 · 대체의사소통체계의 적용에 대한 인식조사. 한국동서정신과학회지, 6(1), 1-13. 최소영, 신문자, 송미승 (2016). 말더듬아동 어머니의 양육경험의 근거이론적 분석. Communication Sciences \& Disorders, 21(4), 719-734.

\section{ORCID}

박현주(제1저자, 교신저자, 교수 http://orcid.org/0000-0002-3868-6381) 